\title{
BMJ Open Gender differences in reporting workplace violence: a qualitative analysis of administrative records of violent episodes experienced by healthcare workers in a large public Italian hospital
}

Daniela Acquadro Maran, ${ }^{1}$ Claudio Giovanni Cortese (1) , ${ }^{1}$ Pierluigi Pavanelli, ${ }^{2}$ Giulio Fornero, ${ }^{2}$ Maria Michela Gianino ${ }^{3}$

To cite: Acquadro Maran D, Cortese CG, Pavanelli P, et al. Gender differences in reporting workplace violence: a qualitative analysis of administrative records of violent episodes experienced by healthcare workers in a large public Italian hospital. BMJ Open 2019;9:e031546. doi:10.1136/ bmjopen-2019-031546

- Prepublication history for this paper is available online. To view these files please visit the journal online (http://dx.doi. org/10.1136/bmjopen-2019031546).

Received 10 May 2019 Revised 17 October 2019 Accepted 22 0ctober 2019

Check for updates

(C) Author(s) (or their employer(s)) 2019. Re-use permitted under CC BY-NC. No commercial re-use. See rights and permissions. Published by BMJ.

${ }^{1}$ Department of Psychology, University of Turin, Torino, Italy

${ }^{2}$ Azienda Ospedaliero

Universitaria Città della Salute $\mathrm{e}$ della Scienza di Torino, Torino, Italy

${ }^{3}$ Department of Public Health Sciences and Pediatrics, University of Turin, Torino, Italy

Correspondence to Professor Claudio Giovanni Cortese;

claudio.cortese@unito.it

\section{ABSTRACT}

Objectives This study aims to analyse, from a descriptive and qualitative point of view, the episodes of violence reported by healthcare workers (HCWs) in a large public Italian hospital. Qualitative analysis permits us to collect the victims' words used to describe the event and the ways in which they dealt with it. A comparison between genders was performed to better understand what type of different strategies could be used to improve the prevention of workplace violence for HCWs.

Design and setting The retrospective observational study was carried out in 'Città della Salute e della Scienza', a complex of four interconnected hospitals situated in Northern Italy. This study analysed aggression data from the 4-year period of 2015-2018 that included all HCW categories. The data were obtained from the aggression reporting form.

Participants The analysed records were supplied by 396 HCWs (3.6\% of all HCWs in the hospital).

Results Male HCWs aged $<30$ years did not report violent episodes that occurred in the workplace, while male HCWs with 6-15 years of work experience reported more violent episodes than their female counterparts. Among the HCW professions, nursing was the profession, in which HCWs were more prone to experience a violent episode, while male medical doctors were more prone to report violent episodes than female medical doctors. Moreover, female HCWs experienced more verbal violence (insults) than male HCWs did, while male HCWs experienced more physical violence (bodily contact) than female HCWs did.

Conclusions The findings from this explorative study suggest that there is a gender difference in the characteristics of workplace violence perpetrated by patients, patients' relatives and visitors and in the way in which these episodes are described. Consequently, it is important for informative and preventive courses to consider gender differences in experiencing a violent episode.
Strengths and limitations of this study

A qualitative analysis was used to collect the victims' descriptions of workplace violence.

- The method permits the capture of respondents points of view.

- The comparison between genders could be useful to improve the prevention of workplace violence in this population.

- It was not possible to overcome the bias in reporting violence.

- Unreported incidents could not be included in the study.

\section{INTRODUCTION}

Workplace violence has been defined by WHO as 'the intentional use of power, threatened or actual, against another person or against a group, in work-related circumstances, that either results in or has a high degree of likelihood of resulting in injury, death, psychological harm, maldevelopment, or deprivation'. ${ }^{1}$

As noted by several investigations, ${ }^{2-4}$ the healthcare sector is at particular risk of workplace violence. Elliott ${ }^{5}$ estimated that the risk of violence from patients and their relatives towards healthcare workers (HCWs) is 16 times higher than that towards other workers. This risk is highest for HCWs working in psychiatric wards and emergency rooms ${ }^{67}$ since they report more violent events than other HCWs, such as those working in wards ${ }^{8-10}$ As suggested by Renwick $e t a l,{ }^{11}$ it is possible that subjects who work in other wards have biassed their answers, presenting themselves as at less risk than they are in reality because of such complex reasons as denial and social stigma of reporting workplace 
violence. At the same time, working in wards with patients who are more dangerous because they suffer from mental illness (psychiatric ward) or are under the influence of drugs or alcohol (emergency room), may make workers who are victims of violence feel more comfortable about reporting violent episodes.

Moreover, the risk of aggression is highest for HCWs working as nurses since they report more violent episodes than do physicians and administrative staff. ${ }^{12}$ A possible explanation for this finding is linked with the nature of their job, as nurses have direct contact with patients (who could be confused, frightened or delirious) and their families/friends. ${ }^{13-15}$ In this case, a possible explanation could be found in the sample bias, since in the literature about nurses being assaulted, respondents who had been assaulted would be expected to have a higher rate of response than those who had not been assaulted. ${ }^{16}$

Another possible explanation is linked to gender: in some countries, such as Italy, in more than $70 \%$ of cases, nurses are female, ${ }^{17}$ and some studies have shown that female workers are more often affected by violence than their male colleagues. ${ }^{18}{ }^{19}$ Gender is also related to the type of violence experienced by HCWs; the investigation by Magnavita and Heponiemi ${ }^{10}$ showed that, in hospitals, female nurses experienced verbal violence (such as yelling and screaming) more often than male nurses, who were more often victims of physical assault (such as hitting and kicking). Moreover, the importance of investigating the gender difference in workplace violence experienced by HCWs was noted by Lawoko et al $^{14}$ : 'intervention/prevention measures need to review the gender and profession issue. It is likely that men and women, psychiatrists and nurses may require different interventions related to their specific problems' (page 51). These types of violent episodes affect the perceived wellbeing of HCWs and could lead to several consequences, such as the interruption of work, medical treatment, and hospital and/or home care; psychological support might be needed for the HCWs to cope with the event. ${ }^{20}$ Workplace violence might also lead staff to leave the profession. ${ }^{21}$

Furthermore, workplace violence in this sector could be related to turnover intention through occupational stress first and then burnout ${ }^{22}$ : regarding this, Kim $e t a l^{23}$ suggested that the prevention of workplace violence is one way of reducing burnout in the healthcare sector.

An interesting question concerns the reports made by HCWs regarding violent episodes in the workplace. Findings from investigations have shown that violence, especially verbal violence, ${ }^{2}$ in the healthcare sector is under-reported. ${ }^{24}{ }^{25}$ The under-reporting of violence is not a phenomenon that involves only workplace violence. All forms of violence (sexual harassment, domestic violence, school bullying, and so on) are under-reported for different reasons, including both the stigma of victimisation, such as shame, isolation, and fear, and the threat of further violence, which often deter victims from reporting violent episodes. ${ }^{26}$
Moreover, for HCWs, there is a risk of desensitisation to violence, as violence-due to contact with frail and ill people-is perceived as part of an HCW's job. ${ }^{27}$ Nevertheless, the reporting of any act of violence is fundamental in engaging hospital management to activate appropriate organisational responses. Indeed, the administrative records of violent episodes experienced by HCWs constitute an important source of information ${ }^{19}$ about the type of violence (physical or verbal), the type of perpetrator (patient, relative or visitor), the type of HCW (administrator, midwife, nurse or physician), the place in which the HCW experienced the violence (psychiatric ward, emergency room or ward) and the type of activity that she/he was doing (support activity for patients, professional team back-office activity, or assistance and patient care). These records permit the prevention of workplace violence, providing information about, for example, the type of training course that a particular HCW subpopulation needs and/or the safety devices that should be installed in a particular ward.

In Europe, the Fifth European Working Conditions Survey $^{28}$ shows that, on average, $14.9 \%$ of workers reported levels of subjection to adverse social behaviour, and the highest level was in the healthcare sector (23\%). The overall percentage of reported levels of subjection to adverse social behaviour in Italian workers was $8 \%$; in the healthcare sector, this percentage was $41.4 \%$ of the workers. ${ }^{29}$ There were 1200 total violent behaviours reported by HWCs in 2018. In most cases, (70\%), the victim was female, and the perpetrator was a patient, a patient's relative or a visitor. ${ }^{30}$ To deal with this phenomenon, in 2007, the Italian Ministry of Health published Recommendation no. 8, 'Preventing acts of violence against health workers'. This recommendation had several goals. First, it oversees the reporting of incidents of violence using official sources, such as the judicial authority, the police forces and the National Workplace Accident Institute. Second, it promotes the collection of data through specific surveys to identify the frequency and severity of violent episodes. The results could be useful for adopting appropriate action from an organisational and structural point of view, for example, redesigning the space and/or reformulating procedures for access to the ward. Moreover, data could be used to improve the training courses that aim to prevent violence, to improve the coping strategies and to reduce the negative consequences. ${ }^{31}$

This study aims to analyse, from a descriptive and qualitative point of view, the episodes of violence experienced by HCWs working in a large public Italian hospital. The qualitative analysis permits us to collect the victims' words used to describe the event and the ways in which they dealt with it. ${ }^{32}$ The advantage offered by this method is that it allows us to capture respondents' points of view without predetermining their answers. ${ }^{334}$ This approach is widely used in social science research ${ }^{35}$ and has been used to investigate HCWs' perceptions of physical and verbal aggression. ${ }^{8637}$ It has also been used, for example, to investigate the descriptions of violent behaviour provided 
by workers ${ }^{38}$ and perceptions of the organisational safety climate. ${ }^{39}$

A comparison between genders was used to better understand what type of differences, if any, could be used to improve the prevention of workplace violence for HCWs. Based on the literature review presented above, the hypothesis is that there are gender differences in the violent episodes experienced by female and male HCWs: female HCWs experience more verbal violence than their male colleagues, and male HCWs experience more physical violence than their female colleagues. Moreover, from the analysis of the episodes, as described by female and male HCWs, we expected that the observed semantic differences characterised the experience of victimisation. This is the novel contribution of this work. We do not have specific hypotheses about the relationship between gender and the lexical words used to define the violent episodes; therefore, we intend to analyse this relationship from an explorative perspective.

\section{METHOD}

The retrospective observational study was carried out in Città della Salute e della Scienza (City of Health and Science University Hub), a complex of four interconnected hospitals situated in Northern Italy. It has 1917 ordinary hospital beds and more than 400-day hospital and day surgery beds, and it is one of the largest national and European health hubs, boasting approximately 12 000 employees. This study analysed aggression data from the 4-year period of 2015-2018 that included all worker categories. The data were obtained from the aggression reporting form adopted in 2014 in compliance with the above-mentioned recommendation of the ministry of health. The form is available on the intranet portal, and all parts of the form must be completed by victims of assault within 72 hours of the event and sent to the Safety and Environment Office. Each administrative record of a violent episode contains the following information: the sociodemographic data of the victim (age, gender, years of experience and profession), workplace in which the violent episode occurred (psychiatric ward, emergency room or ward-one item), the type of activity performed by the HCW at the moment of aggression (ie, conversation), the HCW's shift at the time of aggression, the type of aggressor (the perpetrator could be more than one person: patient, patient's relative or visitor-three items, yes/no answers), the misconduct (violent behaviour could be of more than one type: insult, verbal threat, bodily contact, throwing objects, or use of a weaponfive items, yes/no answers), the consequences (consequences could be of more than one type: interruption of work, medical treatment, psychological support, hospital care, home care or no consequence-five items, yes/no answers), the possibility of preventing the attack (one item, yes/no answer) and the description of the event. Similar to other investigations (see Magnavita and Heponiemi ${ }^{10}$ ), age was categorised as $<30,30-39,40-49$ and $\geq 50$ years, and the years of experience were classified as $\leq 5,6-15,16-25$ and $>25$ years (one item each). The type of activity was categorised as support activity for patients (eg, meal preparation and administration), professional team back-office activity (eg, treatment prescriptions) and assistance and patient care (eg, assistance at the front desk $)^{40}$ (one item). The profession was categorised as midwife, nurse, medical doctor, administrative staff or technician (such as a radiologist) (one item). The work shift in which the aggression occurred was categorised as morning (6:00-00:00 hours), afternoon (00:00-18:00 hours), evening (18:00-24:00 hours) or night (0:00-6:00 hours) (one item).

\section{Procedure}

Data were analysed by the authors of this paper and by assistants trained by researchers. Records were transcribed in a database; sensitive data (name, surname and worker's registration number) were omitted. This procedure was in accordance with the code of ethics of the Italian Association of Professional Psychologists and with Italian law concerning privacy. The files that constituted the corpus of administrative records were saved in a folder. Overall, the sample contained 418 records. The inclusion criteria for the episodes in this analysis were the record describing the case of violence perpetrated by a patient, a relative or a visitor. Thus, 14 records were excluded because the perpetrator was a colleague, a subordinate or a supervisor. Moreover, eight records were excluded because the gender of the victim was omitted. Therefore, 396 records were included in the present work.

\section{Data analysis}

Descriptive statistics were calculated using IBM SPSS Statistics, V.24. Descriptive measures $($ mean $\pm \mathrm{SD}$ ) were calculated for all the continuous variables. Because of the categorical nature of the data, $\chi^{2}$ tests were used to examine gender differences, followed by effect-size calculations (Phi and Cramer's V) to estimate the practical significance of the differences. As a post hoc test, standardised Pearson residuals (from this point forward: SPRs) were calculated for each cell to determine which cell differences contributed to the $\chi^{2}$ test results. SPRs with absolute values greater than 1.96 indicated that the number of cases in that cell was significantly larger than would be expected (in terms of over-representation or under-representation) if the null hypotheses were true, with a significance level of $0.05 .^{41}$

As suggested by Matteucci, Tomasetto, ${ }^{42}$ content analysis was used to process the written description of the violent episodes. Content analysis is defined as the systematic assignment of communication content to categories according to rules and the analysis of relationships involving those categories using statistical methods' [ ${ }^{43} \mathrm{p}$. 3]. These data were analysed using Alceste V.6.0. ${ }^{44}$ This software permits the analysis of written data according to a descending hierarchical classification, in which the text is divided into elementary context units and categorised 


\section{Table 1 Sociodemographic characteristics of the female and male HCWs who experienced violence}

\begin{tabular}{|c|c|c|c|c|}
\hline & $\begin{array}{l}\text { Female } n= \\
302\end{array}$ & $\begin{array}{l}\text { Male } n= \\
94\end{array}$ & $x^{2}$ & $P$ value \\
\hline Age & & & 9.45 & 0.024 \\
\hline$<30$ years & $17(5.7)$ & - & & \\
\hline $30-39$ years & $83(27.9)$ & $18(19.4)$ & & \\
\hline 40-49 years & $105(35.4)$ & $41(44.1)$ & & \\
\hline$\geq 50$ years & $92(31)$ & $34(36.6)$ & & \\
\hline Years of experience & & & 10.24 & 0.017 \\
\hline$\leq 5$ & $44(14.8)$ & $6(6.5)$ & & \\
\hline $6-15$ & $128(43)$ & $53(57)$ & & \\
\hline $16-25$ & $80(26.8)$ & $27(29)$ & & \\
\hline$>25$ & $46(15.4)$ & $7(7.5)$ & & \\
\hline Profession & & & 13.11 & 0.011 \\
\hline Midwife & $39(13.1)$ & $14(15.1)$ & & \\
\hline Nurse & 236(79.2) & $62(66.7)$ & & \\
\hline Medical doctor & $11(3.7)$ & $11(11.8)$ & & \\
\hline $\begin{array}{l}\text { Administrative } \\
\text { staff }\end{array}$ & $9(3)$ & $6(6.5)$ & & \\
\hline Technician & $3(1)$ & - & & \\
\hline Workplace & & & 4.38 & n.s. \\
\hline Psychiatric ward & $35(38.5)$ & $84(28.3)$ & & \\
\hline Emergency room & 104(35) & $23(25.3)$ & & \\
\hline Ward & $109(36.7)$ & 33(36.3) & & \\
\hline Type of activity & & & 3.61 & n.s. \\
\hline $\begin{array}{l}\text { Support activity } \\
\text { for patient }\end{array}$ & $125(45.8)$ & $40(48.8)$ & & \\
\hline $\begin{array}{l}\text { Professional } \\
\text { team's back-office } \\
\text { activity }\end{array}$ & $77(28.2)$ & 15(18.3) & & \\
\hline $\begin{array}{l}\text { Assistance and } \\
\text { patient care }\end{array}$ & $71(26)$ & $27(32.9)$ & & \\
\hline Work shift & & & 0.55 & n.s. \\
\hline Morning & $85(28.5)$ & $30(32.3)$ & & \\
\hline Afternoon & $124(41.6)$ & $36(38.7)$ & & \\
\hline Evening & $64(21.5)$ & $20(21.5)$ & & \\
\hline Night & $25(8.4)$ & $7(7.5)$ & & \\
\hline \multicolumn{5}{|l|}{ Perpetrator } \\
\hline Patient & $173(57.3)$ & $56(59.6)$ & 0.15 & n.s. \\
\hline Patient's relative & $157(52)$ & $35(37.2)$ & 6.25 & 0.012 \\
\hline Visitor & $4(1.3)$ & $5(5.3)$ & 5.15 & 0.023 \\
\hline \multicolumn{5}{|l|}{ Misconduct } \\
\hline Insult & $252(83.4)$ & $67(71.3)$ & 6.78 & .009 \\
\hline Threat & $141(46.7)$ & $42(44.7)$ & 0.12 & n.s. \\
\hline Bodily contact & $77(25.5)$ & $37(39.4)$ & 6.72 & 0.01 \\
\hline Throwing objects & $42(13.9)$ & $20(21.3)$ & 2.95 & n.s. \\
\hline Use of a weapon & $14(4.6)$ & $5(5.3)$ & 0.07 & n.s. \\
\hline \multicolumn{5}{|l|}{ Consequences } \\
\hline $\begin{array}{l}\text { Interruption of } \\
\text { work }\end{array}$ & 61(64.9) & $210(69.8)$ & 0.79 & n.s. \\
\hline
\end{tabular}

Continued
Table 1 Continued

\begin{tabular}{|c|c|c|c|c|}
\hline & $\begin{array}{l}\text { Female } n= \\
302\end{array}$ & $\begin{array}{l}\text { Male } n= \\
94\end{array}$ & $\chi^{2}$ & P value \\
\hline Medical treatment & $29(9.6)$ & $14(15.1)$ & 2.15 & n.s. \\
\hline $\begin{array}{l}\text { Psychological } \\
\text { support }\end{array}$ & $16(5.3)$ & $6(6.4)$ & 0.16 & n.s. \\
\hline Hospital care & $2(0.7)$ & $1(1.1)$ & 0.15 & n.s. \\
\hline Home care & - & $2(2.2)$ & 6.53 & 0.011 \\
\hline No consequences & 64(21.3) & $26(28)$ & 1.76 & n.s. \\
\hline $\begin{array}{l}\text { The attack } \\
\text { could have been } \\
\text { prevented }\end{array}$ & $104(40)$ & $25(29.4)$ & 3.07 & n.s. \\
\hline
\end{tabular}

n.s.=not statistically significant.

The percentages $(n=396)$ are in brackets HCWs, healthcare workers.

into homogeneous classes. The software allows for the isolation and separation of internally homogeneous groups (or classes) within specific populations. Classes are formed on the basis of the co-occurrence of forms and units of context. ${ }^{42}$ The software uses symbols to indicate the type of root. If the word is followed by the symbol $<$, this indicates that only the root of the word is recognised (eg, aggressi <denotes the words aggressive, aggression and aggressively). The symbol +indicates the identification of the termination and of different forms with the same root (eg, nurse +indicates the words nurse and nurses). The first class that is formed will be the most homogeneous in terms of content, that is, the one whose lexical universe (a specific vocabulary that is used and to which the speaker attributes relevant meaning) appears to differ from those of others. The software performs the $\chi^{2}$ test on the association between words and classes to identify the specific vocabulary for each class. This step allows the researcher to identify the lexical worlds in the text, thai is, the 'usual places' (conventional themes) of discourse.$^{45}$ The software allows for repeated segments to be highlighted, that is, associations of the most frequent words in a class and related classes with the selected variables. These are called illustrative variables and carry further information about the textual corpus, allowing the researcher to identify the specific characteristics that define individuals who share the same semantic universe.

In this study, the findings from the descriptive analysis were used as illustrative variables for the text analysis. An example of an illustrative variable is *midwife, which indicates the profession of the HCW who draws up the administrative record to report the violence experienced in the workplace. The resulting data were examined by three independent and autonomous subjects, as suggested by Annese and Mininni. ${ }^{46}$ This phase was followed by a discussion of the meaning attributed to the data to reach an agreement on the results. Consistency was guaranteed by reproducibility (or intercoder reliability ${ }^{47}$; Cohen's $\mathrm{k}=0.85)$. 


\section{Patient and public involvement}

Patients were not involved in the planning and conception of this study.

\section{RESULTS}

\section{Descriptive analysis}

Overall, the records were compiled by 396 HCWs (3.6\% of all HCWs working in the hospital). A total of $302 \mathrm{HCWs}$ $(76.3 \%)$ were female, representing approximately $4 \%$ of the entire female HCW population; 94 (23.7\%) were male, representing $3.1 \%$ of the entire male HCW population. Most of the HCWs were aged 40-49 years (146, $36.9 \% ; 4.7 \%$ of the entire HCW population aged $40-49$ years). Regarding years of experience, most HCWs were in the range of $6-15$ years $(181,46.3 \% ; 6.1 \%$ of the entire HCW population with $6-15$ years of experience). Two hundred and ninety-eight HCWs $(76.2 \%)$ were nurses (26.6\% of the entire nurse population), 53 (13.6\%) were midwives (25.4\% of the entire midwife population), 22 $(5.6 \%)$ were medical doctors $(1.2 \%$ of the entire medical doctor population), 15 (3.8\%) were administrative staff (1.7\% of the entire administrative staff population) and $3(0.8 \%)$ were technicians $(0.5 \%$ of the entire technician population). Table 1 presents the sociodemographic characteristics of the female and male HCWs who experienced violence.

Regarding the age of the victims, the findings showed a statistically significant difference between genders (Cramer's V=0.16). In particular, there were no male victims aged $<30$ years $(|\mathrm{SPR}|=-2.0)$. Male $\mathrm{HCW}$ with
Table 2 Findings from text corpus of administrative records compiled by female HCW victims of workplace violence

\begin{tabular}{lclc}
\hline \multicolumn{2}{l}{ Class I-waiting time } & \multicolumn{3}{l}{ Class II-physical attack } \\
\hline Words & $\chi^{2}$ & Words & $\chi^{2}$ \\
Visit< & 20 & Kick+ & 88 \\
Wait< & 17 & Agitat< & 76 \\
Therap+ & 13 & Cris+ & 69 \\
Work< & 12 & Personal+ & 63 \\
Triage & 11 & Object+ & 56 \\
Illustrative variables: & Illustrative variables: \\
emergency room, ward & psychiatric ward, midwife \\
\hline
\end{tabular}

HCW, healthcare worker.

6-15 years of experience referred more frequently to episodes of violence ( $|\mathrm{SPR}|=1.7$, Cramer's $\mathrm{V}=0.16$ ) than did female HCWs. Moreover, male medical doctors referred more frequently to episodes of violence than did female doctors, and these episodes of violence occurred more frequently for male medical doctors ( $|\mathrm{SPR}|=2.5$, Cramer's V=0.18). The perpetrator was a patient's relative for more female HCWs than male HCWs ( $52 \%$ and $37.2 \%$, respectively, $\mathrm{p}=0.012$ ), while the perpetrator was a visitor for more male HCWs than female HCWs $(5.3 \%$ and $1.3 \%$, respectively, $\mathrm{p}=0.023)$. Regarding consequences, home care was indicated by male HCWs, while female HCWs did not mention it.

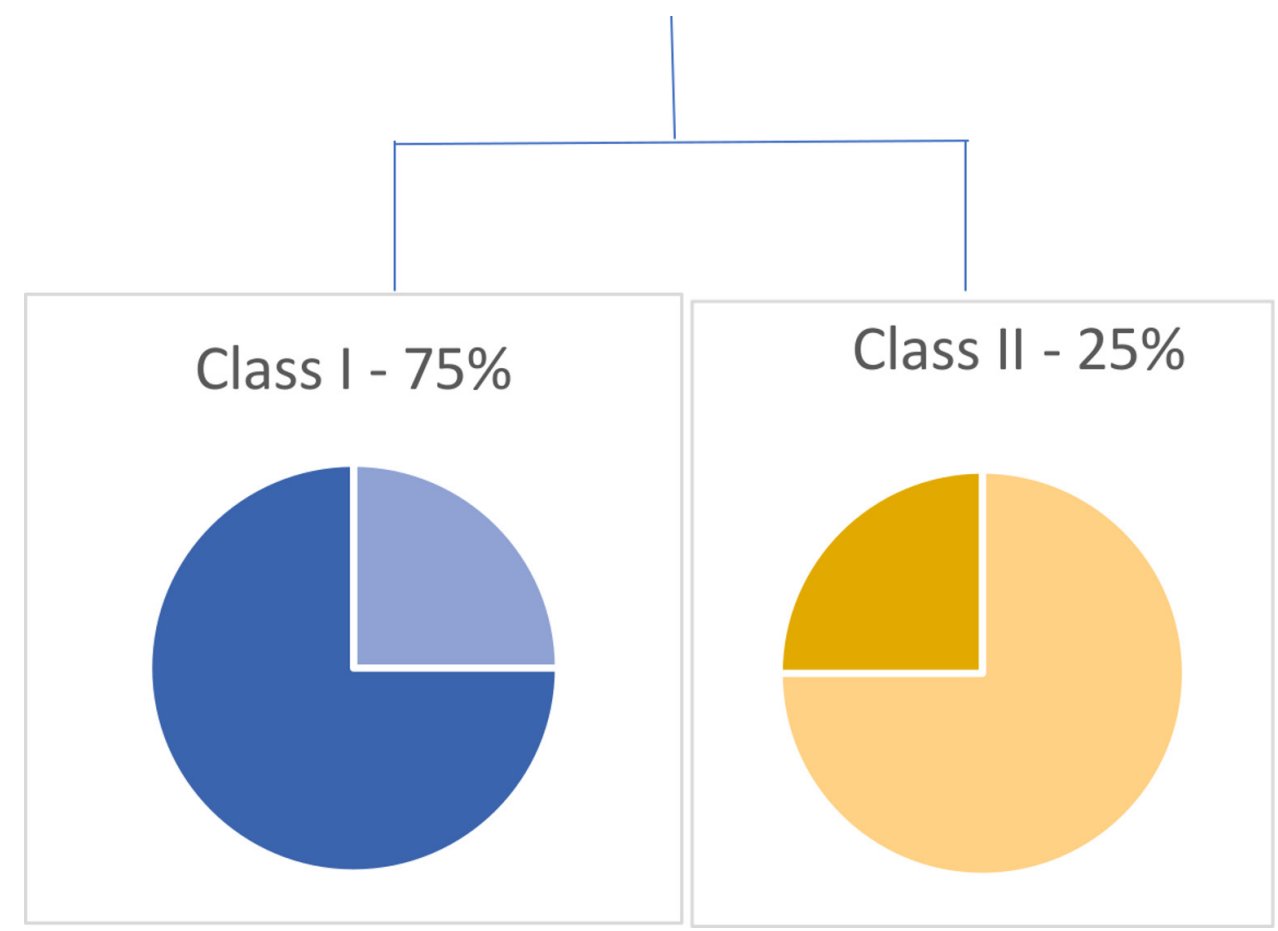

Figure 1 Text corpus of administrative records compiled by female HCWs victims of workplace violence. The dendrogram shows the classification procedure used to create the two classes that emerged (amount of variance explained=96.9\%). Class I explained $75 \%$ of the variance and was labelled waiting time. Class II explained $25 \%$ of the variance and was labelled physical attack. HCWs, healthcare workers. 


\section{Text analysis}

Based on findings from the descriptive analysis, age, years of experience and profession were used as illustrative variables. The analysis of the administrative record drawn up by female HCWs showed that the corpus was composed of 14951 occurrences (frequency of words in absolute values), 2739 distinct forms (words with frequency $>3$; mean frequency=13 per form) and 1345 hapax (words used only once, occurrences with a frequency=1). The overall number of elementary context units was 516. The five most frequent words (associated forms) in the corpus were patient $+(n=329)$, aggressi $<(n=125)$, medic $<$ $(n=62)$, wait $<(n=61)$ and staff $(n=39)$. The dendrogram of stable classes (figure 1) shows the classification procedure used to create the two classes that emerged (amount of variance explained $=96.9 \%$ ). For each class, the first characterising five words are presented in order of the $\chi^{2}$ results (table 2), together with the associated illustrative variables.

Class I explained $75 \%$ of the variance and was labelled Waiting time. The most representative words in terms of $\chi^{2}$ describe the violent episodes as a consequence of patients and relatives waiting for a visit or therapy or of the assignment of degrees of urgency to wounds or illnesses to decide the order in which patients will be treated. This waiting time was considered by the perpetrator as unacceptable. The following sentence is an example of how a female HCW described a violent episode.

The patient's relatives were complaining about the waiting time. They could tell that the staff were overworked. The patient's son and daughter repeatedly came into the emergency room instead of waiting in the hall. The patient's son said to not annoy him because otherwise there would be trouble (nurse, aged 30-39years, 6-15years of work)

Class II explained $25 \%$ of the variance and was labelled Physical attack. This lexical world refers to the behaviours demonstrated by psychiatric patients during routine activities, such as the distribution of meals. Perpetrators were described as patients who suffered from a psychotic crisis and who physically assaulted an HCW. The sentence below provides an example of a respondent's textual production.

At the end of the dinner, the patient had a crisis; he became aggressive with staff that was around him and kicked me in the face, cutting my upper lip (midwife, aged 30-39years, 6-15years of experience)

The analysis of the administrative record drawn up by male HCWs showed that the corpus was composed of 3804 occurrences, 1271 distinct forms (mean frequency $=9$ per form) and 795 hapax, that is, words used only once. The overall number of elementary context units was 144 . The five most frequent words (associated forms) in the corpus were patient+ $(n=103)$, aggressi< $(n=34)$, threat $+(n=29)$, person $<(n=26)$ and medic $<(n=20)$. The dendrogram of stable classes (figure 2) shows the classification procedure used to create the five classes that emerged (amount of variance explained $=93.6 \%$ ). For each class, the first characterising five words are presented in order of the $\mathrm{X}^{2}$ results (table 3 ), together with the associated illustrative variables.

The dendrogram (figure 2) shows the classification procedure used to create the five classes that emerged and highlights which classes are closer and therefore

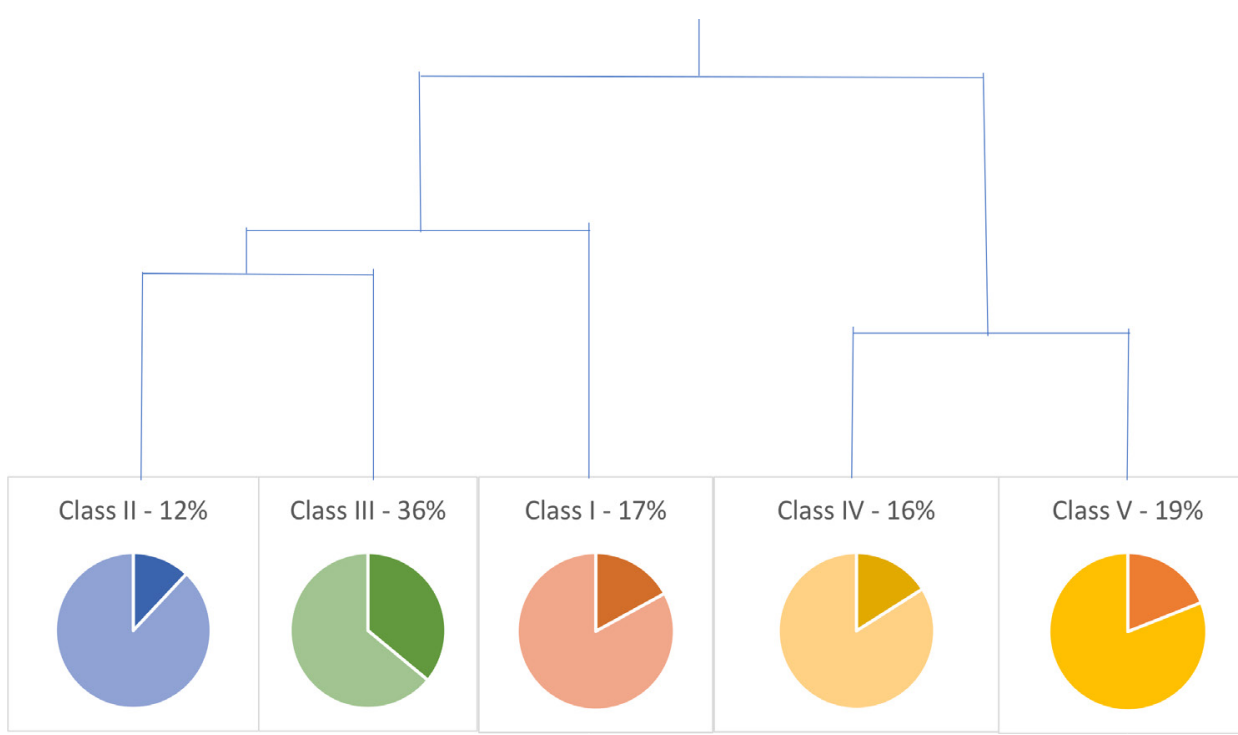

Figure 2 Text corpus of administrative records compiled by male HCWs victims of workplace violence. The dendrogram shows the classification procedure used to create the five classes that emerged (amount of variance explained=93.6\%). The dendrogram shows that classes I-III are more similar than classes IV and V. At the same time, classes IV and V are more similar than the other classes. Classes I-III explain - together - 65\% of the variance; classes IV and V explain $35 \%$ of the variance. Classes I-III were labelled verbal violence. Classes IV and V were labelled Corporeal assault. HCWs, healthcare worker. 


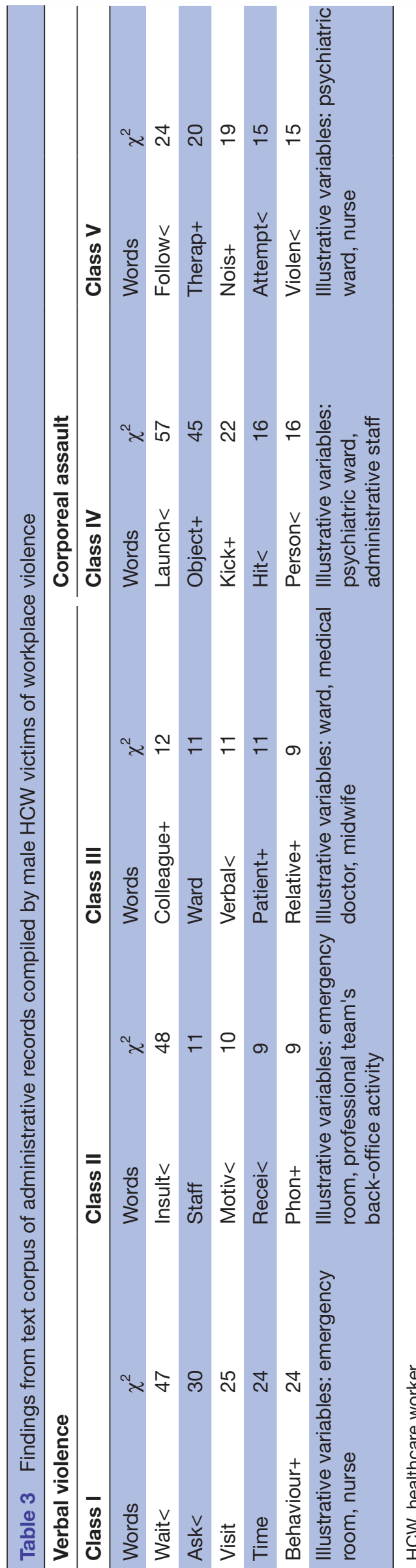

more similar. Specifically, the dendrogram shows that classes I-III are more similar than classes IV and V. At the same time, classes IV and V are more similar than the other classes. Classes I-III explain-together-65\% of the variance; Classes IV and V explain $35 \%$ of the variance.

Classes I-III were labelled Verbal violence. The words characterising these classes were related to violent behaviours-such as insults and threats-that HCWs experienced principally in the emergency room and ward, both through direct contact (face to face) and by phone. In these episodes, one or more colleagues were involved. Below are some examples from the descriptions of violent events made by male HCWs:

Before the conclusion of the visit, the father started to attack me verbally. He told me 'I pay the taxes, I ask you to do everything, I do not go out until the child has a diagnosis'. After reiterating that it is not possible to perform this exam in an emergency room, the father threatened me and the nurse verbally, repeatedly (medical doctor, aged 40-49years, $6-15$ years of experience)

I phoned the patient's son to inform him of the imminent discharge of his father. I was insulted with elevated tone repeatedly. It was impossible to manage communication; I did not reply in any way to the insults (nurse, 6-15years of experience)

The patient's husband accused me and my colleague of not respecting the numbering in the call for assistance. The colleague explained to him that there is a work plan, but he verbally attacked us (nurse, aged $\geq 50$ years, $16-25$ years of experience)

Classes IV and V were labelled Corporeal assault. The words characterising these classes were related to physical violent behaviours-such as hitting and throwing objects-which HCWs experienced principally in the psychiatric ward. Below are some examples of sentences from administrative records:

While my colleague and I were preparing a medication, we were interrupted by the noise of shots coming from the kitchen door. Then, we were reached for and assaulted by the patient (nurse, aged $>50$ years, $6-15$ years of experience)

An agitated patient-for no apparent reasonpushed a cart against the entrance door to break through. He was shunted out, and then he came back and threatened to break our arms (administrative staff, aged 40-49years, 16-25 years of experience)

\section{DISCUSSION}

The findings from the descriptive analysis showed some differences based on the HCW's gender. Male HCWs aged $<30$ years did not report violent episodes that occurred in the workplace, while male HCWs with 6-15years of 
experience reported more violent episodes than their female counterparts did. Among the HCW professions, nursing was the profession in which HCWs were more prone to experience a violent episode, confirming the results of. ${ }^{11}$ Nevertheless, the findings showed that male medical doctors were more prone to report violent episodes than female medical doctors. Confirming the findings of Magnavita and Heponiemi, ${ }^{10}$ in this study, female HCWs experienced more verbal violence (insults) than male HCWs did, while male HCWs experienced more physical violence (bodily contact) than female HCWs did. Thus, our hypothesis was confirmed. An interesting finding concerns the perpetrator: female HCWs experienced a violent episode acted out by a patient's relative more often than male HCWs did, and male HCWs experienced a violent episode acted out by a visitor more often than female HCWs did. Regarding the workplace, type of activity, and work shift, no statistically significant difference between genders emerged. This finding did not confirm the results of Magnavita and Heponiemi, ${ }^{10}$ as in this study, it was not found that male HCWs experienced workplace violence in wards more often than female HCWs did.

Text analyses showed that female and male HCWs reported violent episodes in different ways. The findings from the text analysis of female HCWs identified a contextual factor for the violent episodes that occurred principally in those who were working in emergency rooms and wards. This contextual factor is the waiting time, a condition in which a patient and a patient's relative-as suggested by Schablon et $a l^{15}$-could experience anxiety, confusion and fear. Moreover, female HCWs (in particular, midwives) describe the violent episodes that occurred in the psychiatric ward as a consequence of a mental health disorder and noted that the assault was unpredictable. Thus, it seems that female HCWs perceive dealing with violence as part of their role. ${ }^{48}$ Male HCWs use different words to describe violent episodes. They, more often than female HCWs, described the episodes including the witness of the episode, namely, colleagues. Male HCWs described episodes that occurred in the emergency room and ward (verbal violence) and in the psychiatric ward (corporeal assault) in the same way that female HCWs did. These episodes were related more to the type of profession than to the gender of the HCWs. The other illustrative variables (age and years of experience) did not have an effect on the differences between how male and female HCWs experience violent episodes.

This study has strengths and limitations. Regarding strengths, in this study, administrative records in which HCWs experienced violent episodes were used. Usually, self-administered questionnaires are used to collect data about workplace violence. However, self-assessment could be affected by recall bias ${ }^{49}$; thus, this method does not solve the problem of over-reporting or under-reporting: a long study period could also influence the victim's memory. The analysis of reports completed within 72 hours of the aggression permits the retrieval of important information about the episode. Moreover, in this study, a qualitative analysis was used to identify differences between genders in reporting these episodes. According to Griffiths and Schabracq,$^{50}$ the majority of studies in work and health psychology and investigations on workplace violence use a quantitative approach: this choice stems from the fact that this method allows large numbers of subjects to complete standardised questionnaires. Otherwise, a qualitative approach permits the gathering of the complexity and nuances of individual experiences and reveals the range of ways in which common features operate in experiences of workplace violence. ${ }^{51}$ Indeed, this method was useful to better understand the lexicon that characterised the victimisation experienced by female and male HCWs.

This study also has weaknesses. First, because HCWs decided whether to report violent episodes, the results cannot be generalised and should be taken with caution. Thus, it was not possible to overcome the bias in reporting violence, as HCWs may be more likely to report serious events and exclude less serious ones. ${ }^{24}$ Future research should explore, in a more comprehensive way, this phenomenon within health organisations. For example, interviews and focus group discussion techniques could be used to better understand the obtained results and how to promote the reporting of all violent behaviour, not only the most serious events: as recommended by the Italian Ministry of Health, ${ }^{31}$ a better comprehension of workplace violence could be useful to prevent it. Another limitation is in the procedure adopted: administrative records had different styles of reports, which we tried to make homogeneous through a classification procedure. This process included a subjective component, which must be considered in any narrative analysis. ${ }^{52}$ The use of a mixed-method technique could permit the description of the phenomenon by a quantitative and qualitative approach. Future research could use this technique to expand the scope and improve the analytic power of studies on workplace violence in the healthcare sector. ${ }^{53}$

\section{CONCLUSIONS}

Overall, the findings from this explorative study suggest that there is a gender difference in the characteristics of workplace violence perpetrated by patients, patients' relatives and visitors and in the way in which these episodes are described. Consequently, as noted by Lawoko et $a l^{14}$ and Chen $e t a l,{ }^{19}$ it is important in informative and preventive courses to consider gender differences in experiencing a violent episode. For female HCWs, it could be useful to provide clear messages that the acceptance of such violence is not 'part of the job', ${ }^{27} 54$ explaining that anger should not be taken as an acceptable emotion in the healthcare environment and that exposure to verbal violence should not be accepted as a hazard of the profession. ${ }^{55}$ For male HCWs, it could be useful to reflect on feelings related to the stigma of victimisation and to stress that a witness is not necessary to corroborate a male HCW's version of the event. This finding could be 
analysed in greater depth through an investigation that involves witnesses of the violent episodes describing the episodes from their points of view: a follow-up study could include interviews with staff on gender differences in the long-term impact of these events.

Moreover, these findings could be used by health organisation management to better organise the security arrangements in some departments, to manage the overload of the emergency room and to increase the use of safety devices.

In conclusion, the findings could be used by health organisation management to improve individual measures, such as intervention programmes, counselling and psychological help, to reflect on victimisation experiences and the way in which female and male HCWs react to and cope with workplace violence.

\section{Twitter Claudio Giovanni Cortese @cgcortese}

Acknowledgements The authors thank Daniela Cosentino and Andrea Caputo (MS in Psychology) for their assistance in the transcription of the administrative records.

Contributors Conceptualisation: DAM, CGC and MMG; methodology: DAM; investigation: DAM, PP, GF and MMG; data analysis: DAM; writing (original draft preparation): DAM and CGC; writing (review and editing): DAM, CGC and MMG.

Funding The authors have not declared a specific grant for this research from any funding agency in the public, commercial or not-for-profit sectors.

Competing interests None declared.

Patient consent for publication Not required

Ethics approval The Local Ethics Committee (Comitato di Bioetica dell'Ateneo, University of Torino) approved the research project in 17 January 2019 (Prot. 19468).

Provenance and peer review Not commissioned; externally peer reviewed. Data availability statement № data are available.

Open access This is an open access article distributed in accordance with the Creative Commons Attribution Non Commercial (CC BY-NC 4.0) license, which permits others to distribute, remix, adapt, build upon this work non-commercially, and license their derivative works on different terms, provided the original work is properly cited, appropriate credit is given, any changes made indicated, and the use is non-commercial. See: http://creativecommons.org/licenses/by-nc/4.0/.

\section{ORCID iD}

Claudio Giovanni Cortese http://orcid.org/0000-0003-2339-9838

\section{REFERENCES}

1 WHO. Violence: a public health priority. Geneva: World Health Organization, 1995.

2 Cooper CL, Swanson N. Workplace violence in the health sector. state of the art. Geneva: Organización Internacional de Trabajo, Organización Mundial de la Salud, Consejo Internacional de Enfermeras Internacional de Servicios Públicos, 2002.

3 Phillips JP. Workplace violence against health care workers in the United States. N Engl J Med 2016;374:1661-9.

4 Sun P, Zhang X, Sun Y, et al. Workplace violence against health care workers in North Chinese hospitals: a cross-sectional survey. Int $J$ Environ Res Public Health 2017;14:96.

5 Elliott PP. Violence in healthcare. Nurs Manage 1997:38-41.

6 Grottoli E, Ciriello S, Gabriele M, et al. [Assaults and nuisances in health care environment]. G Ital Med Lav Ergon 2007;29:653-5.

7 lozzino L, Ferrari C, Large M, et al. Prevalence and risk factors of violence by psychiatric acute inpatients: a systematic review and meta-analysis. PLoS One 2015;10:e0128536.

8 Arnetz JE, Hamblin L, Essenmacher L, et al. Understanding patientto-worker violence in hospitals: a qualitative analysis of documented incident reports. J Adv Nurs 2015;71:338-48.

9 Kim SC, Ideker K, Todicheeney-Mannes D. Usefulness of aggressive behaviour risk assessment tool for prospectively identifying violent patients in medical and surgical units. J Adv Nurs 2012;68:349-57.
10 Magnavita N, Heponiemi T. Violence towards health care workers in a public health care facility in Italy: a repeated cross-sectional study. BMC Health Serv Res 2012;12:108.

11 Renwick L, Lavelle M, James K, et al. The physical and mental health of acute psychiatric ward staff, and its relationship to experience of physical violence. Int J Ment Health Nurs 2019;28:268-77.

12 Hahn S, Hantikainen V, Needham I, et al. Patient and visitor violence in the General Hospital, occurrence, staff interventions and consequences: a cross-sectional survey. J Adv Nurs 2012;68:2685-99.

13 Ahmad M, Al-Rimawi R, Masadeh A, et al. Workplace violence by patients and their families against nurses: literature review. Int J Nurs Health Sci 2015;2:46-55.

14 Lawoko S, Soares * JJF, Nolan P. Violence towards psychiatric staff: a comparison of gender, job and environmental characteristics in England and Sweden. Work Stress 2004;18:39-55.

15 Schablon A, Wendeler D, Kozak A, et al. Prevalence and consequences of aggression and violence towards nursing and care staff in Germany-A survey. Int $J$ Environ Res Public Health 2018;15:1274.

16 Maguire BJ, O'Meara P, O'Neill BJ, et al. Violence against emergency medical services personnel: a systematic review of the literature. $\mathrm{Am}$ $J$ Ind Med 2018;61:167-80.

17 Italian Ministry of health. Personale delle A.S.L. E degli istituti di cura pubblici. Available: www.salute.gov.it/imgs/C_17_pubblicazioni_ 2161_allegato.pdf

18 Morganson VJ, Brown SE. Gender and Sexualized Aggression in the Workplace. In: Nadler JY, Lowery MR, eds. The war on women in the United States: beliefs, tactics, and the best defenses. 2018. Praeger Publishing, 2051

19 Chen C, Smith PM, Mustard C. Gender differences in injuries attributed to workplace violence in Ontario 2002-2015. Occup Environ Med 2019;76:3-9.

20 Itzhaki M, Peles-Bortz A, Kostistky H, et al. Exposure of mental health nurses to violence associated with job stress, life satisfaction, staff resilience, and post-traumatic growth. Int J Ment Health Nurs 2015;24:403-12.

21 Hampton D, Rayens MK. Impact of psychological empowerment on workplace bullying and intent to leave. J Nurs Adm 2019;49:179-85.

22 Laeeque SH, Bilal A, Babar S, et al. How patient-perpetrated workplace violence leads to turnover intention among nurses: the mediating mechanism of occupational stress and burnout. J Aggress Maltreat Trauma 2018;27:96-118.

$23 \mathrm{Kim} \mathrm{H}$, Kim J-S, Choe K, et al. Mediating effects of workplace violence on the relationships between emotional labour and burnout among clinical nurses. J Adv Nurs 2018;74:2331-9.

24 Findorff MJ, McGovern PM, Wall MM, et al. Reporting violence to a health care employer: a cross-sectional study. AAOHN Journal 2005;53:399-406.

25 Gillespie GL, Leming-Lee Treasa (Susie), Crutcher T, et al. Chart it to stop it. J Nurs Care Qual 2016;31:254-61.

26 Clements PT, DeRanieri JT, Clark K, et al. Workplace violence and corporate policy for health care settings. Nur Econ 2005;23:119-24.

27 Kennedy MP. Violence in emergency departments: under-reported, unconstrained, and unconscionable. Med J Aust 2005;183:362-5.

28 Eurofound. Fifth European working conditions survey. Luxembourg: Publication Office of the European Union, 2012. https://www. eurofound.europa.eu/it/publications/report/2012/workingconditions/fifth-european-working-conditions-survey-overviewreport

29 Istat. II disagio nelle relazioni lavorative. Istat, 2010. Available: https:// www.istat.it/it/archivio/5191

30 Inail. Violenza, aggressione E non solo. Dati Inail, 2018. Available: https://www.inail.it/cs/internet/docs/alg-dati-inail-2018-novembre. pdf

31. Ministero della Salute. Raccomandazione per prevenire Gli atti di violenza a danno degli operatori sanitari. Raccomandazione N. 8, novembre, 2007. Available: http://www.salute.gov.it/portale/ documentazione/p6_2_2_1.jsp?id=721

32 Hopkins L, Taylor L, Bowen E, et al. A qualitative study investigating adolescents' understanding of aggression, bullying and violence. Child Youth Serv Rev 2013;35:685-93.

33 Patton MQ. Qualitative research and evaluation methods. thousand oaks. CA: Sage, 2002: 339-427.

34 Ritchie J, Lewis J, Nicholls CM. Qualitative research practice: a guide for social science students and researchers. Thousand Oaks CA: Sage, 2013.

35 Fetters MD, Curry LA, Creswell JW. Achieving integration in mixed methods Designs-Principles and practices. Health Serv Res 2013;48:2134-56. 
36 Ramacciati N, Ceccagnoli A, Addey B, et al. Violence towards emergency nurses. The Italian national survey 2016: a qualitative study. Int J Nurs Stud 2018;81:21-9.

37 Shahzad A, Malik RK. Workplace violence: an extensive issue for nurses in Pakistan - a qualitative investigation. J Interpers Violence 2014;29:2021-34.

38 Pattani R, Ginsburg S, Mascarenhas Johnson A, et al. Organizational factors contributing to Incivility at an academic medical center and systems-based solutions. Academic Medicine 2018;93:1569-75.

39 Arnetz J, Hamblin LE, Sudan S, et al. Organizational determinants of workplace violence against hospital workers. Journal of Occupational and Environmental Medicine 2018;60:693-9.

40 Tucker AL, Spear SJ. Operational failures and interruptions in hospital nursing. Health Serv Res 2006;41:643-62.

41 Agresti A. Categorical data analysis. 3st edn. Hoboken, New Jersey: John Wiley \& Sons, 2002: 267-313.

42 Matteucci MC, Tomasetto C. Alceste: un software per l'analisi dei dati testuali. In: Mazzara BM, ed. Metodi qualitativi in psicologia sociale. Roma: Carocci, 2002: 305-27.

43 Riff D, Lacy S, Fico F. Analyzing media messages: using quantitative content analysis in research. New York: Routledge, 2014.

44 Reinert M. Un logiciel d'analyse lexicale. Cahiers de l'analyse des données 1986;11:471-81.

45 Reinert M. Mondes lexicaux et topoi dans l'approche de Alceste. [Lexical worlds and topoi in Alceste approach]. In: Mellet S, Vuillome $M$, eds. Mots chiffrés et déchiffrés [Coded and decoded words. Paris, France: Honoré Champion Editeur, 1998: 289-303.
46 Annese S, Mininni G. La focus group discussion tra analisi de contenuto e analisi del discorso. In: Mazzara BM, ed. Metodi qualitativi in psicologia sociale. Roma: Carocci, 2002: 125-48.

47 Burla L, Knierim B, Barth J, et al. From text to codings: intercoder reliability assessment in qualitative content analysis. Nurs Res 2008;57:113-7

48 Brockmann M. New perspectives on violence in social care. Journal of Social Work 2002;2:29-44.

49 Brophy JT, Keith MM, Hurley M. Assaulted and unheard: violence against healthcare staff. New Solut 2018;27:581-606.

50 Griffiths A, Schabracq MJ. Work and health psychology as a scientific discipline: Facing the limits of the natural science paradigm. In: Schabracq MJ, Winnubst JAM, Cooper CL, eds. The Handbook of work and health psychology. New York: Wiley, 2003: 173-89.

51 Coyle A. Introduction to qualitative psychological research. In: Lyons $\mathrm{E}$, Coyle A, eds. Analysing qualitative data in psychology. Thousand Oaks, CA: Sage Publications, 2007: 9-29.

52 Amaratunga D, Baldry D, Sarshar M, et al. Quantitative and qualitative research in the built environment: application of "mixed" research approach. Work Study 2002;51:17-31.

53 Sandelowski M. Combining qualitative and quantitative sampling, data collection, and analysis techniques in Mixed-Method studies. Res Nurs Health 2000;23:246-55.

54 Potera C. Violence against nurses in the workplace. AJN, American Journal of Nursing 2016;116:20-1.

55 Duxbury J, Whittington R. Causes and management of patient aggression and violence: staff and patient perspectives. J Adv Nurs 2005;50:469-78. 